\title{
Kinetics and mechanism of oxidation of $n$-butylamine and 1,3-propanediamine by potassium ferrate
}

\author{
Jinhuan Shan, Yafeng Yang and Jinhuan Shan* \\ College of Chemistry and Environmental Science, Hebei University, Baoding, 071002, China \\ ${ }^{*}$ Corresponding author at: College of Chemistry and Environmental Science, Hebei University, Baoding, 071002, China. Tel.: +86.0312.5971129; \\ fax:+86.0312.5079525. E-mail address: shanjinhuaner@yahoo.com.cn (J. Shan).
}

\begin{tabular}{l} 
ARTICLE INFORMATION \\
Received: 06 January 2011 \\
Received in revised form: 01 March 2011 \\
Accepted: 18 April 2011 \\
Online: 30 September 2011 \\
KEYWORDS \\
\hline$n$-Butylamine \\
1,3-propanediamine \\
Potassium ferrate \\
Kinetics and mechanism \\
Oxidation \\
Environmental protection
\end{tabular}

\begin{abstract}
The kinetics of oxidation of $n$-butylamine and 1,3-propanediamine by home-made potassium ferrate(VI) at different conditions has been studied spectrophotometrically in the temperature range of 283.2-298.2 K. The results show first order dependence on potassium ferrate (VI) and on each reductant. The observed rate constant ( $k_{\mathrm{obs}}$ ) decreases with the increase of $\left[\mathrm{OH}^{-}\right]$, and the reaction rate has a negative fraction order with respect to $\left[\mathrm{OH}^{-}\right]$. A plausible mechanism is proposed and the rate equations derived from the mechanism was shown to fit all the experimental results. The rate constants of the rate-determining step and the thermodynamic activation parameters are calculated.
\end{abstract}

\section{Introduction}

Potassium ferrate, which is an effective and multifunctional water treatment agent, has strong oxidation capacity in aqueous solutions [1-4] because of the unusually high oxidation state of iron. Its reduction product Fe(III) is not toxic. It integrates the properties, such as oxidizing sterilization, adsorption, flocculation, and deodorization, without causing secondary pollution in wastewater treatment. As the understanding of ferrate is further developed, the study of its application value becomes more and more important. Because of its strong ability of oxidation, which can be deduced from its electrode potential, ferrate can oxidize many substances, including inorganic compounds and ions such as $\mathrm{S}_{2} \mathrm{O}_{4}{ }^{2-}, \mathrm{SCN}^{-}$, $\mathrm{H}_{2} \mathrm{~S}$ etc. [5-7] and organic compounds such as alcohol, acid, hydroxyl ketone, hydrogen quinonoids, benzene, oxime etc. [810] without any hazard to human and environment.

In 1974, Goff and Murmann published the first kinetic study for the ferrate oxidation of hydrogen peroxide and sulfite along with an oxygen exchange study [11]. Bielski and Sharma reported the oxidation of amino acids by ferrate occurs via oneelectron radical pathways [12]. In his system, the oxidation occurs by a one-electron pathway to produce $\mathrm{Fe}(\mathrm{V})$ and then $\mathrm{Fe}(\mathrm{V})$ rapidly undergoes a two-electron transfer to form an inner-sphere Fe(III) complex [13]. The exact mechanism by which this occurs is not known. In contrast to the one-electron mechanisms suggested by Bielski, Johnson and Lee have proposed two-electron reductions of ferrate. Johnson favored a quasi-stable ferrate/substrate bridged intermediate for the reaction with thiosulfate [14]. The proposed bridged species contains an ester linked, Fe-O-S moiety ( $\mathrm{S}=$ substrate) accompanied by consecutive two-electron reductions of $\mathrm{Fe}(\mathrm{VI})$ that results in Fe(II). Direct oxygen transfer was observed by oxygen tracer studies thereby supporting this mechanism. To date, relatively few kinetic studies of such systems have appeared in the literature.

$n$-Butylamine can be used as cracked gasoline antigumagent, petroleum products additive, chromatype developer, emulsifier, etc. [15]. Also, it is an intermediate to produce drugs and pesticides. $n$-Butylamine is a toxic compound, with strong alkalinity and corrosivity. Its solution or vapors can intensely stimulate eyes, skin and mucous membrane. Inhaling large amounts of its vapor causes headache, nausea, even pulmonary edema. 1,3-Propanediamine is mainly used as scavenger and intermediate in organic synthesis. Its toxicity is more than $n$-butylamine. The inhaling can cause bronchial spasm, inflammation, edema, chemical pneumonia or pulmonary edema and death. In this paper, the kinetics and mechanism of oxidation of $n$-butylamine and 1,3propanediamine by potassium ferrate were studied in detail.

\section{Experimental}

\subsection{Materials, apparatus and kinetic measurements}

Measurements of the kinetics were performed using a TU1900 spectrophotometer (Beijing Puxi Inc., China) fitted with a DC-2010 thermostat $( \pm 0.1 \mathrm{~K}$, Baoding, China). All solutions were prepared with doubly distilled water. Potassium ferrate $\left(\mathrm{K}_{2} \mathrm{FeO}_{4}\right)$ was prepared by the method of Thompson et al. [16]. The concentration of $\mathrm{K}_{2} \mathrm{FeO}_{4}$ was derived from its absorption at $507 \mathrm{~nm}\left(\varepsilon=1.15 \times 10^{3} \mathrm{~L} / \mathrm{mol} \cdot \mathrm{cm}\right)$. The solution of $\mathrm{K}_{2} \mathrm{FeO}_{4}$ was always freshly prepared before use. $n$-Butylamine and 1,3propanediamine are made in Beijing Chemical Reagent Company. The oxidants and reductants were both dissolved in buffer solution which contained required concentration of $\mathrm{KNO}_{3}$ and $\mathrm{Na}_{2} \mathrm{HPO}_{4}$ to maintain ionic strength and acidity of the reaction respectively. The reaction was initiated by mixing the 
$\mathrm{Fe}(\mathrm{VI})$ to reductant solution and the process was monitored the decrease in concentration of all the Fe(VI) species with time ( $\mathrm{t}$ ) automatically by recording absorbance at $507 \mathrm{~nm}$ on a TU1900 spectrophotometer while other species did not absorb significantly at this wavelength (Figure 1). All kinetics measurements were carried out under pseudo-first order conditions.

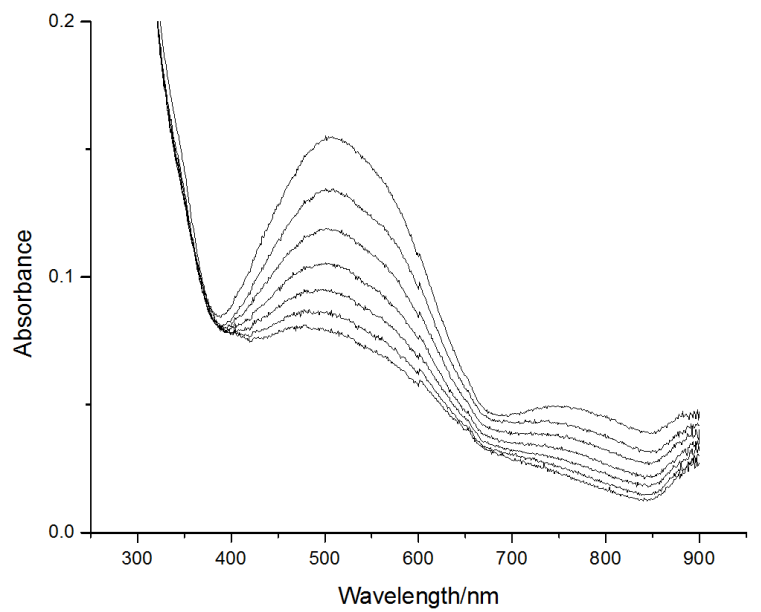

Figure 1. Plots of reduction of oxidant absorption peak through the reaction. $[\mathrm{Fe}(\mathrm{VI})]=1.56 \times 10^{-4} \mathrm{~mol} / \mathrm{L},[n$-butylamine $]=0.02 \mathrm{~mol} / \mathrm{L},[\mathrm{OH}-]=1.07 \times 10^{-4}$ $\mathrm{mol} / \mathrm{L}, \mathrm{I}=1.00 \mathrm{~mol} / \mathrm{L}, \mathrm{T}=283.2 \mathrm{~K}$.

\subsection{Product analysis}

Determination of reduction product of $\mathrm{Fe}(\mathrm{VI})$ : The reduction product of $\mathrm{Fe}(\mathrm{VI})$ was identified as $\mathrm{Fe}(\mathrm{III})$ by the color reaction of $\mathrm{K}_{3} \mathrm{Fe}(\mathrm{CN})_{6} / \mathrm{K}_{4} \mathrm{Fe}(\mathrm{CN})_{6}$ and 2,2-bipyridyl [17]. The result showed no color change on $\mathrm{K}_{3} \mathrm{Fe}(\mathrm{CN})_{6}$ or 2,2-bipyridyl but Prussian blue stain on $\mathrm{K}_{4} \mathrm{Fe}(\mathrm{CN})_{6}$.

Determination of oxidation product of reductant: Ammonia was detected through the reaction by using the method of the reference [18], which proves that amino of the reductant was oxidized to ammonia.

Determination of reaction intermediate: Presence of Fe(II) was confirmed by 1,10-phenanthroline test. The color change indicates that $\mathrm{Fe}(\text { phen })_{3}{ }^{2-}$ was generated in the process of the reaction, which proves Fe(II) has once appeared [10].

\section{Results and discussion}

\subsection{Determination of pseudo-first order rate constants}

\subsubsection{Rate dependence on [Fe(VI)]}

Under the conditions where [reductant $]_{0} \gg[\mathrm{Fe}(\mathrm{VI})]_{0}$, the plots of $\ln \left(A_{t}-A_{\infty}\right)$ versus time $t$ were straight line (Figure 2 ), indicating the reaction is first order with respect to the $\mathrm{Fe}(\mathrm{VI})$ complex, where $A_{t}$ and $A_{\infty}$ are the absorbance at time $t$ and at infinite time respectively.

\subsubsection{Rate dependence on [reductant]}

The pseudo-first-order rate constants $k_{\text {obs }}$ were calculated by the method of least squares $(r \geq 0.999)$. The $k_{\text {obs }}$ values were the average values of at least three independent experiments, and reproducibility is within $\pm 5 \%$. At fixed $[\mathrm{Fe}(\mathrm{VI})],\left[\mathrm{OH}^{-}\right]$and ionic strength I, the values of $k_{\text {obs }}$ were determined at different temperatures. The $k_{\text {obs }}$ were found to increase with the increase of reactant concentration. The plots of $k_{\text {obs }}$ versus [reductant] were linear. For the plots passed through the grid origin
(Figure 3 and 4), the reaction was first order with respect to reductant.

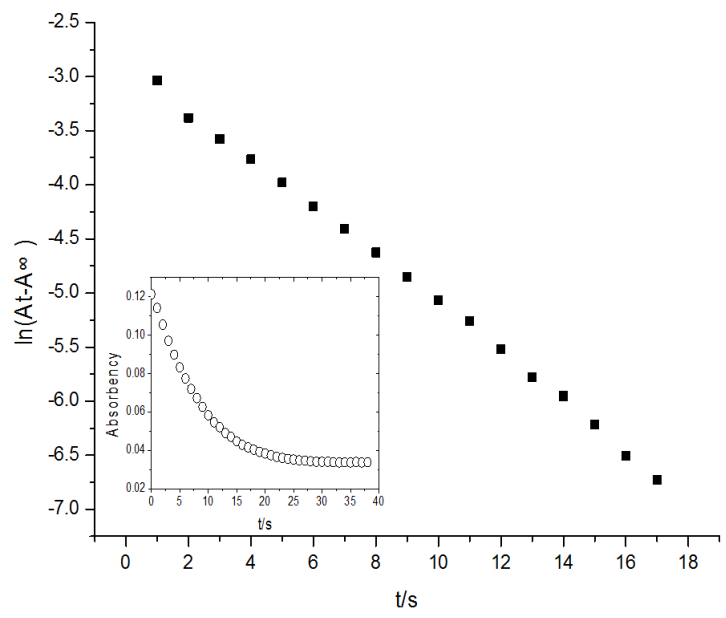

Figure 2. Plots of $\ln (\mathrm{At}-\mathrm{A} \infty)$ versus time t. $[\mathrm{Fe}(\mathrm{VI})]=1.56 \times 10^{-4} \mathrm{~mol} / \mathrm{L}$, $[1,3$-propanediamine $]=0.025 \mathrm{~mol} / \mathrm{L},\left[\mathrm{OH}^{-}\right]=1.17 \times 10^{-4} \mathrm{~mol} / \mathrm{L}, \mathrm{I}=1.00$ $\mathrm{mol} / \mathrm{L}, \mathrm{T}=298.2 \mathrm{~K}(r=0.9993)$.

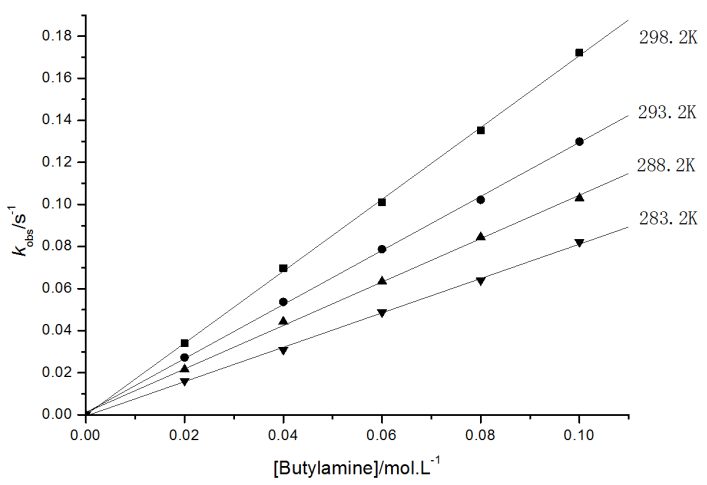

Figure 3. Plots of $k_{\text {obs }}$ versus [ $n$-butylamine] at different temperatures. $[\mathrm{Fe}(\mathrm{VI})]=1.56 \times 10^{-4} \mathrm{~mol} / \mathrm{L},\left[\mathrm{OH}^{-}\right]=1.07 \times 10^{-4} \mathrm{~mol} / \mathrm{L}, \mathrm{I}=1.00 \mathrm{~mol} / \mathrm{L}$ $(r>0.999)$.

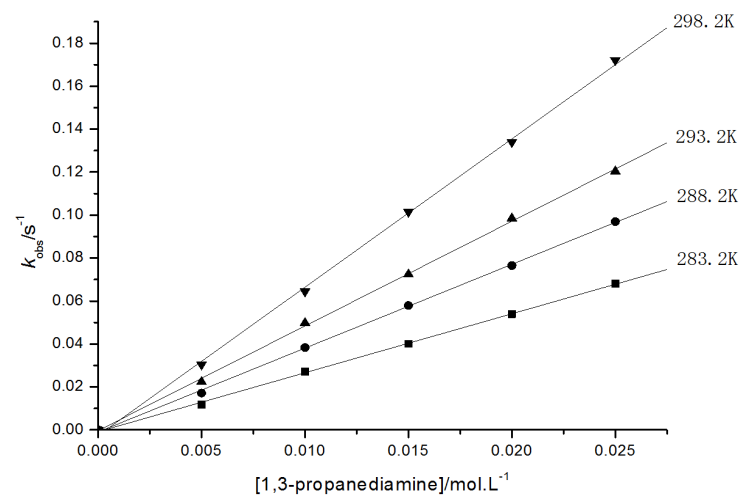

Figure 4. Plots of $k_{\text {obs }}$ versus [1,3-propanediamine] at different temperatures. $[\mathrm{Fe}(\mathrm{VI})]=1.56 \times 10^{-4} \mathrm{~mol} / \mathrm{L},\left[\mathrm{OH}^{-}\right]=1.17 \times 10^{-4} \mathrm{~mol} / \mathrm{L}, \mathrm{I}=1.00$ $\mathrm{mol} / \mathrm{L}(r>0.999)$.

\subsubsection{Rate dependence on [OH-]}

At fixed [Fe(VI)], [reductant], ionic strength $I$ and temperature, the values of $k_{\text {obs }}$ decreased with the increase of 
$\left[\mathrm{OH}^{-}\right]$. The order with respect to $\left[\mathrm{OH}^{-}\right]$was found to be a negative fraction, which indicates that there is a balance of $\left[\mathrm{OH}^{-}\right.$ ] generation before the speed-control step [19]. The trendlines of $1 / k_{\text {obs }}$ versus $\left[\mathrm{OH}^{-}\right]$(Figure 5 and 6 ) show that the plots didn't pass through the grid origin.

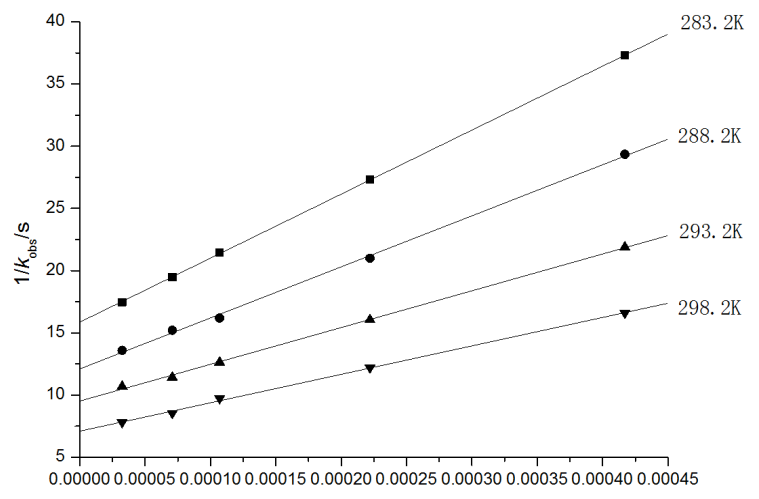

$[\mathrm{OH}] / \mathrm{mol}^{-L^{-1}}$

Figure 5. Plots of $1 / k_{\mathrm{obs}}$ versus $\left[\mathrm{OH}^{-}\right]$at different temperatures. $[\mathrm{Fe}(\mathrm{VI})]=$ $1.56 \times 10^{-4} \mathrm{~mol} / \mathrm{L},[n$-butylamine $]=0.06 \mathrm{~mol} / \mathrm{L}, \mathrm{I}=1.00 \mathrm{~mol} / \mathrm{L}(r>0.999)$.

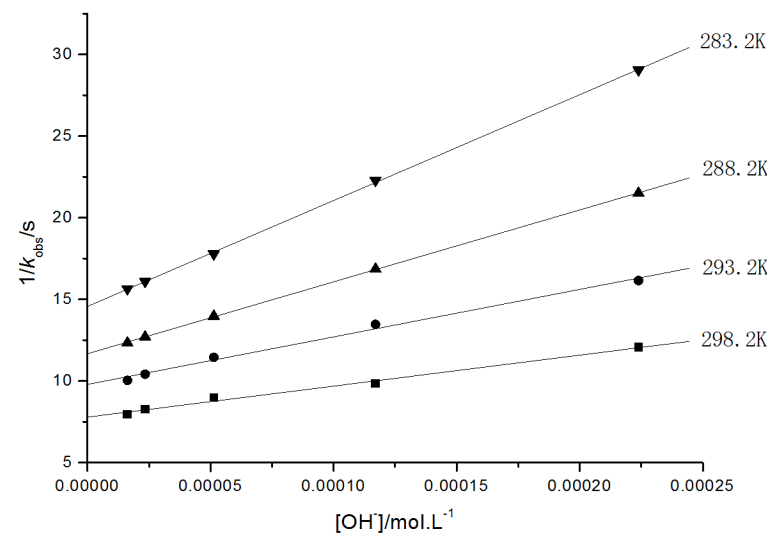

Figure 6. Plots of $1 / k_{\text {obs }}$ versus $\left[\mathrm{OH}^{-}\right]$at different temperatures. $[\mathrm{Fe}(\mathrm{VI})]=$ $1.56 \times 10^{-4} \mathrm{~mol} / \mathrm{L},[1,3-$ propanediamine $]=0.015 \mathrm{~mol} / \mathrm{L}, \quad \mathrm{I}=1.00 \mathrm{~mol} / \mathrm{L}$ $(r>0.996)$.

\subsection{Reaction mechanism}

James Carr [8] has put forward a rate equation which contains three terms as follows:

Rate $=\mathrm{k}_{1}\left[\mathrm{FeO}_{4}{ }^{2-}\right]+\mathrm{k}_{2}\left[\mathrm{FeO}_{4}{ }^{2-}\right]^{2}+\mathrm{k}\left[\mathrm{FeO}_{4}{ }^{2-}\right][\mathrm{S}](\mathrm{S}=$ substrate $)$

James Carr thought that the first two terms are the contribution of the self-decomposition rate of $\mathrm{K}_{2} \mathrm{FeO}_{4}$ to the reaction system when there is no substrate. Under the experimental conditions presented in this paper, the selfdecomposition rate of $\mathrm{K}_{2} \mathrm{FeO}_{4}$ is far less than the oxidation rate of the reductant, so we can represent the rate equation as follows which is consistent with James Carr in essence:

Rate $=\mathrm{k}\left[\mathrm{FeO}_{4}{ }^{2-}\right][\mathrm{R}]$ (R=reductant)

Ferrate(VI) is a diacid [20], where:

$\begin{array}{ll}\mathrm{H}_{2} \mathrm{FeO}_{4} \rightleftharpoons \mathrm{HFeO}_{4}^{-}+\mathrm{H}^{+} & \mathrm{pKa} a_{1}=3.5 \\ \mathrm{HFeO}_{4}^{-} \rightleftharpoons \mathrm{H}^{+}+\mathrm{FeO}_{4}{ }^{2-} & \mathrm{pK} a_{2}=7.8\end{array}$

Then, part of $\mathrm{FeO}_{4}{ }^{2-}$ will take hydrolysis as follows:

$\mathrm{FeO}_{4}^{2-}+\mathrm{H}_{2} \mathrm{O} \rightleftharpoons \mathrm{HFeO}_{4}^{-}+\mathrm{OH}^{-}$

Hence: $K_{h}=\frac{\left[\mathrm{HFeO}_{4}{ }^{-}\right]\left[\mathrm{OH}^{-}\right]}{\left[\mathrm{FeO}_{4}{ }^{2-}\right]}=\frac{K w}{K a_{2}}=6.31 \times 10^{-7}$

This experiment is performed at $\mathrm{pH}=10.03$ and 10.07 , then there is

$\frac{\left[\mathrm{HFeO}_{4}^{-}\right]}{\left[\mathrm{FeO}_{4}^{2-}\right]}=\frac{K_{h}}{\left[\mathrm{OH}^{-}\right]}=5.90 \times 10^{-3}$ and $5.39 \times 10^{-3}$

Although the concentration of $\mathrm{HFeO}_{4}$ - is very small, it is easy for it to form a six-membered ring complex with the reductant in the presence of a hydrogen atom. The formed complex has higher activity towards anion [21]. Under the attack of hydroxyl, the complex dissociates into Fe(IV) and at the same time releases ammonia. The probable reaction process takes place as given in Scheme 1.

Then, as an intermediate, Fe(IV) is much more active than $\mathrm{Fe}(\mathrm{VI})$ [21], and it continues to react further with another molecule of reductant to generate Fe(II). Therefore, the reaction takes place mainly through $\mathrm{HFeO}_{4}{ }^{-}$. According to discussion, the following reaction mechanism is proposed:

$$
\begin{aligned}
& \mathrm{FeO}_{4}^{2-}+\mathrm{H}_{2} \mathrm{O} \stackrel{k h}{\longrightarrow} \mathrm{HFeO}_{4}^{-}+\mathrm{OH}^{-} \\
& \mathrm{HFeO}_{4}-\mathrm{R} \underset{k_{-2}}{\stackrel{k_{2}}{\longrightarrow} \mathrm{X}} \\
& \mathrm{X}+\mathrm{OH}^{-} \stackrel{k_{3}}{\longrightarrow} \mathrm{Fe}(\mathrm{IV})+\mathrm{P} \text { (product) } \\
& \mathrm{Fe}(\mathrm{IV})+\mathrm{R} \stackrel{k_{4}}{\longrightarrow} \mathrm{Fe}(\mathrm{II})+\mathrm{P} \text { (product) } \\
& \mathrm{Fe}(\mathrm{IV})+\mathrm{Fe}(\mathrm{II}) \stackrel{k_{5}}{\longrightarrow} \mathrm{Fe}(\mathrm{III})
\end{aligned}
$$

Reaction (9) is the rate-determining step. As the rate of the disappearance of $\left[\mathrm{FeO}_{4}{ }^{2-}\right]$ was monitored, the rate of the reaction can be derived as:

$-\frac{d\left[\mathrm{FeO}_{4}{ }^{2-}\right]}{d \mathrm{t}}=k_{2}\left[\mathrm{HFeO}_{4}^{-}\right][\mathrm{R}]-k_{-2}[\mathrm{X}]$

After steady-state processing:

$[\mathrm{X}]=\frac{k_{2}\left[\mathrm{FeO}_{4}^{-}\right][\mathrm{R}]}{k_{-2}+k_{3}\left[\mathrm{OH}^{-}\right]}$

Then we get the rate equation:

$-\frac{d\left[\mathrm{FeO}_{4}^{2-}\right]}{d \mathrm{t}}=\frac{k_{2} k_{3}\left[\mathrm{HFeO}_{4}^{-}\right][\mathrm{R}]\left[\mathrm{OH}^{-}\right]}{k_{-2}+k_{3}\left[\mathrm{OH}^{-}\right]}$

Equation (16) can be obtained from (8):

$\left[\mathrm{HFeO}_{4}^{-}\right]=\frac{K_{h}\left[\mathrm{FeO}_{4}{ }^{2-}\right]}{\left[\mathrm{OH}^{-}\right]}$ 
Table 1. Rate constants $\left(k_{2}\right)$ and thermodynamic activation parameters of the rate-determining step $(\mathrm{T}=298.2 \mathrm{~K})$.

\begin{tabular}{|c|c|c|c|c|c|}
\hline \multicolumn{2}{|l|}{$\underline{\mathbf{T}(\mathrm{K})}$} & \multirow{2}{*}{283.2} & \multirow{2}{*}{$\begin{array}{r}\mathbf{2 8 8 . 2} \\
643.89\end{array}$} & \multirow{2}{*}{$\begin{array}{c}\mathbf{2 9 3 . 2} \\
894.03\end{array}$} & \multirow{2}{*}{$\begin{array}{c}\mathbf{2 9 8 . 2} \\
1156.10\end{array}$} \\
\hline & $n$-butylamine & & & & \\
\hline$k_{2} / \mathrm{mol}^{-1} \cdot \mathrm{L} \cdot \mathrm{s}^{-1}$ & 1,3-propanediamine & 1629.22 & 2399.00 & 3632.35 & 5566.98 \\
\hline Thermodynamic activation parameters (298.2 K) & $\begin{array}{l}n \text {-butylamine } \\
1,3 \text {-propanediamine }\end{array}$ & \multicolumn{4}{|c|}{$\begin{aligned} \mathrm{Ea} & =38.78 \mathrm{~kJ} / \mathrm{mol}, \Delta \mathrm{H}^{\neq}=36.31 \mathrm{~kJ} / \mathrm{mol}, \Delta \mathrm{S}^{\neq}=-64.60 \mathrm{~J} / \mathrm{K} \cdot \mathrm{mol} \\
\mathrm{Ea} & =57.56 \mathrm{~kJ} / \mathrm{mol}, \Delta \mathrm{H}^{\neq}=55.08 \mathrm{~kJ} / \mathrm{mol}, \Delta \mathrm{S}^{\neq}=11.28 \mathrm{~J} / \mathrm{K} \cdot \mathrm{mol}\end{aligned}$} \\
\hline
\end{tabular}

Table 2. The values of $10^{3} \times k_{\mathrm{obs}}$ experimental and calculated at different temperatures ([OH- $]=1.07 \times 10^{-4} \mathrm{~mol} / \mathrm{L}, r=n$-butylamine).

\begin{tabular}{|c|c|c|c|c|c|c|c|c|}
\hline \multirow{2}{*}{$\begin{array}{ll}\mathrm{C} / \mathrm{mol}^{\prime} \mathrm{L}^{-1} & \mathrm{~T} / \mathrm{K} \\
\end{array}$} & \multicolumn{2}{|c|}{283.2} & \multicolumn{2}{|c|}{ 288.2 } & \multicolumn{2}{|c|}{293.2} & \multicolumn{2}{|c|}{298.2} \\
\hline & EXP & CAL & EXP & CAL & EXP & CAL & EXP & CAL \\
\hline 0.02 & 15.58 & 15.60 & 21.26 & 20.20 & 27.18 & 26.27 & 34.04 & 34.90 \\
\hline 0.04 & 31.83 & 31.19 & 44.38 & 40.41 & 53.73 & 52.55 & 69.75 & 69.81 \\
\hline 0.06 & 47.87 & 46.79 & 61.68 & 60.61 & 78.75 & 78.82 & 101.09 & 104.71 \\
\hline 0.08 & 62.91 & 62.39 & 78.59 & 80.81 & 102.24 & 105.09 & 135.32 & 139.62 \\
\hline 0.10 & 77.69 & 77.98 & 103.06 & 101.02 & 129.94 & 131.36 & 172.14 & 174.52 \\
\hline
\end{tabular}

Table 3. The values of $10^{3} \times k_{\mathrm{obs}}$ experimental and calculated at different temperatures $\left(\left[\mathrm{OH}^{-}\right]=1.17 \times 10^{-4} \mathrm{~mol} / \mathrm{L}, r=1,3\right.$-propanediamine).

\begin{tabular}{|c|c|c|c|c|c|c|c|c|}
\hline \multirow{2}{*}{$\begin{array}{ll}\mathrm{C} / \mathrm{mol}^{-\mathrm{L}^{-1}} & \mathrm{~T} / \mathrm{K} \\
\end{array}$} & \multicolumn{2}{|c|}{283.2} & \multicolumn{2}{|c|}{288.2} & \multicolumn{2}{|c|}{293.2} & \multicolumn{2}{|c|}{298.2} \\
\hline & EXP & CAL & EXP & CAL & EXP & CAL & EXP & CAL \\
\hline 0.005 & 11.86 & 15.04 & 17.19 & 18.31 & 23.22 & 25.26 & 30.38 & 33.30 \\
\hline 0.010 & 30.02 & 30.08 & 38.32 & 36.61 & 49.80 & 50.52 & 65.29 & 66.60 \\
\hline 0.015 & 44.88 & 45.12 & 57.91 & 54.93 & 74.23 & 75.78 & 101.47 & 99.90 \\
\hline 0.020 & 53.97 & 60.16 & 74.14 & 73.24 & 101.97 & 101.04 & 133.92 & 133.20 \\
\hline 0.025 & 75.51 & 75.21 & 93.01 & 91.55 & 128.15 & 126.30 & 172.04 & 166.50 \\
\hline
\end{tabular}

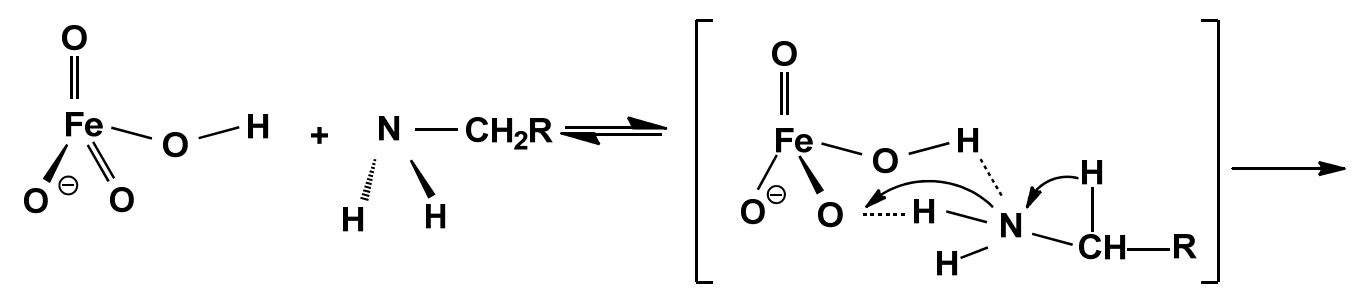

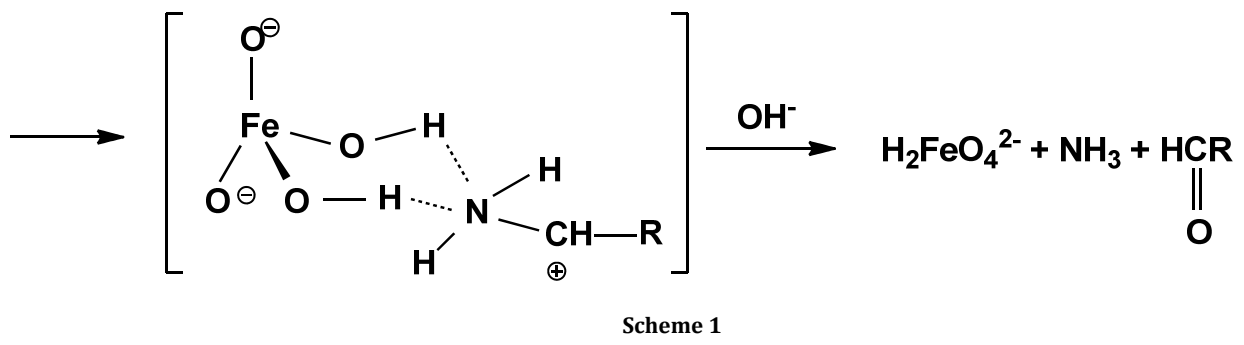

Substituting equation (16) into (15), we can get the following equation:

$$
\begin{aligned}
& -\frac{d\left[\mathrm{FeO}_{4}{ }^{2-}\right]}{d \mathrm{t}}=\frac{k_{2} k_{3} K_{h}\left[\mathrm{FeO}_{4}{ }^{2-}\right][\mathrm{R}]}{k_{-2}+k_{3}\left[\mathrm{OH}^{-}\right]}=\frac{k_{2} k_{3} K_{h}[\mathrm{R}]}{k_{-2}+k_{3}\left[\mathrm{OH}^{-}\right]}\left[\mathrm{FeO}_{4}{ }^{2-}\right] \\
& k_{\mathrm{obs}}=\frac{k_{2} k_{3} K_{h}[\mathrm{R}]}{k_{-2}+k_{3}\left[\mathrm{OH}^{-}\right]}=\frac{k_{2} k^{\prime} K_{h}[\mathrm{R}]}{1+k^{\prime}\left[\mathrm{OH}^{-}\right]}
\end{aligned}
$$

in the equation $k^{\prime}=k_{3} / k_{-2}$

$$
\frac{1}{k_{\mathrm{obs}}}=\frac{1+k^{\prime}\left[\mathrm{OH}^{-}\right]}{k_{2} k^{\prime} K_{h}[\mathrm{R}]}=\frac{1}{k_{2} k^{\prime} K_{h}[\mathrm{R}]}+\frac{\left[\mathrm{OH}^{-}\right]}{k_{2} K_{h}[\mathrm{R}]}
$$

These equations indicate that the reaction should be first order both with respect to $\mathrm{Fe}(\mathrm{VI})$ and reductant. The plot of $1 / k_{\text {obs }}$ versus $\left[\mathrm{OH}^{-}\right]$derives from equation (19) at constant [R] is linear with positive intercept. These are consistent with the experimental phenomena.

As the plots of $1 / k_{\text {obs }}$ versus [ $\left.\mathrm{OH}^{-}\right]$were shown in Figure 5 and 6 , the rate-determining step rate constants $\left(k_{2}\right)$ could be evaluated, and the thermodynamic activation parameters were obtained (Table 1) [22] with the help of their slopes and equation (19).

Meanwhile, with the help of equation (19), the values of $k^{\prime}$ under corresponding temperature could be calculated using the slopes and intercepts of Figure 5 and 6 . Then, substituting $k^{\prime}, k_{2}$ and $\left[\mathrm{OH}^{-}\right]$into equation (18), we can calculate the rate constants under corresponding [R], which are very close to the experimental values (Table 2 and 3 ). This illustrates that the equation (19) is correct and the reaction mechanism we proposed is reasonable. 


\section{Conclusion}

The discussion and results presented in this paper demonstrate that the reaction of potassium ferrate with $n$-butylamine and 1,3-propanediamine both take place by twoelectron transfer. First, $\mathrm{Fe}(\mathrm{VI})$ reacts with a molecule of reductant to form Fe(IV) and product, then Fe(IV) with another molecule of reductant react further to generate Fe(II) and product. At last, $\mathrm{Fe}(\mathrm{IV})$ reacts with $\mathrm{Fe}(\mathrm{II})$ to generate $\mathrm{Fe}(\mathrm{III})$. The results show first order dependence on potassium ferrate (VI) and on each reductant and the reaction is negative fraction order with respect to [OH-]. At the same time we also observed the rate of the rate-determining step of 1,3-propanediamine is quicker than that of $n$-butylamine, and the rate constants of the rate-determining step for 1,3-propanediamine is larger than those for $n$-butylamine. The activation energy of 1,3-propanediamine is larger than $n$-butylamine. The reason for this should be that the reaction between 1,3-propanediamine and $\mathrm{Fe}(\mathrm{VI})$ are simultaneous on both amino groups, there is more resistance. The activation parameters are all in support of the mechanism and consistent with experimental phenomena.

\section{Acknowledgement}

Thanks for the supply of equipments and reagents demanded in this experiment by Hebei University.

\section{References}

[1]. Jiang, J. Q.; Lloyd, B. Water Res. 2002, 36, 1397-1408.

[2]. Jiang, J. Q.; Alex, P.; Mike B. J. Eniron. Managem. 2006, 79(2), 215-220.

[3]. Li, C.; Li, X. Z.; Graham N. Water Res. 2008, 42(1-2), 109-120.

[4]. Zhang, J.; Shi, Q. L.; Yang, G. M. Environ. Prot. Chem. Ind. 2000, 20, 4447.

[5]. Sharma, V. K.; Burnett, C. R.; Yngard, R. A. Environ. Sci. Technol. 2005, 39(10), 3849-3854.

[6]. Sharma, V. K. Adv. Environ. Res. 2002, 6(2), 143-156.

[7]. Sharma, V. K.; Smith, J. O.; Millero, F. J. Environ. Sci. Technol. 1997, 31, 2486-2491.

[8]. James, D. C. Environ. Sci. Technol. 1981, 15, 184-187.

[9]. James, D. C. Trans. Metal Chem. 1986, 11,116-117.

[10]. James, D. C.; Kelter, P. B. Anal. Chem. 1979, 51(11), 1828-1834

[11]. Goff, H.; Murmann, R. K. J. Am. Chem. Soc. 1971, 93, 6058-6065.

[12]. Bielski, B. H. J.; Sharma, V. K. Inorg. Chem. 1991, 30, 4306-4310.

[13]. Bielski, B. H. J.; Rush, J. D. Free Radical Res. 1995, 22, 571-579.

[14]. Johnson, M. D.; Reed, J. F. Inorg. Chem. 1996, 35, 6795-6799.

[15]. Meng, Y.; Xu, Z. S.; Chen, L. G.; Li, Y.; Dong, F. J. Chem. Ind. Eng. 1998, 15(4), 44-48.

[16]. Thompson, G. W.; Ockerman, L. T.; Schreyer, J. M. J. Am. Chem. Soc. 1951, 73, 1379-1381.

[17]. Dong, W. X. Detection of all kinds of Ions in the Chemical Method, Beijing Normal University Press, Beijing, 1984, pp. 94.

[18]. Han, B. X. Rapid detection method of inorganic ions, People's education press, Beijing, 1979, pp. 10.

[19]. Han, D. G.; Gao, P. L. Foundation of chemical kinetics, Beijing University Press, Beijing, 1987, pp. 212.

[20]. James, D. C.; Kelter, P. B.; Tabatabai, A.; Spichal, D.; Erickson, J.; McLaughlin, C. W. Environ. Impact Health Eff. 1985, 5, 1285-1298.

[21]. Jezowska-Trzebiatowska, B. Catal. Chem. Kinet. 1964, 212-217.

[22]. Shan, J. H.; Liu, T. Y. Acta Chem. Sinica. 1994, 52, 1140-1144. 